\title{
Untreated distal intimal tears may be associated with paraplegia after total arch replacement and frozen elephant trunk treatment of acute Stanford type A aortic dissection
}

\author{
Ling Tan, MD, ${ }^{\mathrm{a}}$ Jun Xiao, MD, ${ }^{\mathrm{a}}$ Xinmin Zhou, MD, ${ }^{\mathrm{a}}$ Kangjun Shen, MD, ${ }^{\mathrm{a}}$ Feng Li, MD, \\ Jianguang Luo, MD, ${ }^{\mathrm{b}}$ and Hao Tang, $\mathrm{MD}^{\mathrm{a}}$
}

\section{ABSTRACT}

Objective: To investigate the possible overlooked causes of early postoperative paraplegia, a severe complication of acute Stanford type A aortic dissection (ATAAD) after total arch replacement and frozen elephant trunk (FET).

Methods: We reviewed the clinical data and perioperative aortic computed tomography angiography records of 110 consecutive patients with ATAAD who underwent total arch replacement and FET $(12 \mathrm{~cm})$ between December 2014 and September 2017 and investigated the possible risk factors related to early postoperative paraplegia.

Results: Paraplegia occurred in $5(4.5 \%)$ patients. No significant differences were found between patients with and without paraplegia in terms of sex, age, medical history, cardiopulmonary bypass time, antegrade cerebral perfusion time, rectal temperature during antegrade cerebral perfusion, postoperative hypotension, maximum first 24-hour vasoactive-inotropic score, upper-lower pressure gradient, or false lumen thrombosis. Postoperative aortic computed tomography angiography showed a "cutoff" phenomenon in the lower descending aorta in 4 of the 5 patients. Univariate logistical analysis showed that paraplegia was associated with the "cutoff" phenomenon $(P<.05)$. The patients with a distance $\geq 30 \mathrm{~mm}$ from the distal end of the stent to the first untreated intimal tear had significantly greater rates of the "cutoff" phenomenon and paraplegia than those with the distance $<30 \mathrm{~mm}(P<.05)$.

Conclusions: Total arch replacement and FET is safe and feasible for ATAAD involving the descending aorta. Early postoperative paraplegia is associated with the "cutoff" phenomenon in the lower descending aorta. The position of the first untreated intimal tear may be related with the occurrence of the "cutoff" phenomenon and paraplegia. (J Thorac Cardiovasc Surg 2019;158:343-50)

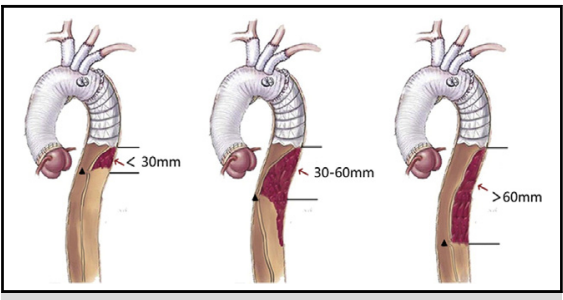

Different distances from the stent end to the first tear result in thrombosis models.

\section{Central Message}

We reviewed clinical data and aortic CTA of 110 patients with ATAAD who underwent total arch replacement combined with FET and investigated possible risk factors related to early postoperative paraplegia.

\section{Perspective}

Early postoperative paraplegia was associated with the "cutoff" phenomenon in lower descending aorta. The position of the first untreated intimal tear may be related with the occurrence of the "cutoff" phenomenon and paraplegia. Using a short stent alone is insufficient to avoid postoperative paraplegia. Surgeons should pay more attention to the first untreated intimal tear beyond the end of the stent.

See Commentaries on pages 351 and 353.
Acute Stanford type A aortic dissection (ATAAD) leads to a high mortality within a short period, and emergent surgery is still the only effective treatment. ${ }^{1}$ Proximal repair and contemporary extended arch repair are 2 surgical

\footnotetext{
From the Departments of ${ }^{\mathrm{a} C}$ ardiovascular Surgery, and ${ }^{\mathrm{b}}$ Interventional Radiography, the Second Xiangya Hospital of Central South University, Changsha, Hunan, PR China.

Received for publication Jan 20, 2018; revisions received Aug 9, 2018; accepted for publication Aug 22, 2018; available ahead of print Nov 3, 2018.

Address for reprints: Hao Tang, MD, Department of Cardiovascular Surgery, the Second Xiangya Hospital, Central South University, and NO 139. Renmin Rd, Changsha, Hunan, 410011, PR China (E-mail: dr.tanghao@csu.edu.cn). $0022-5223 / \$ 36.00$

Copyright (C) 2018 by The American Association for Thoracic Surgery https://doi.org/10.1016/j.jtcvs.2018.08.111
}

therapeutic strategies for ATAAD involving the descending aorta. With the improvements in surgical procedures and artificial blood vessels, such as the innovation of extended arch repair (simultaneous replacement of the ascending aorta, the total aortic arch, and integrated stent grafting of the descending aorta) with frozen elephant trunk (FET) in $2003,{ }^{2}$ the postoperative mortality of patients with ATAAD

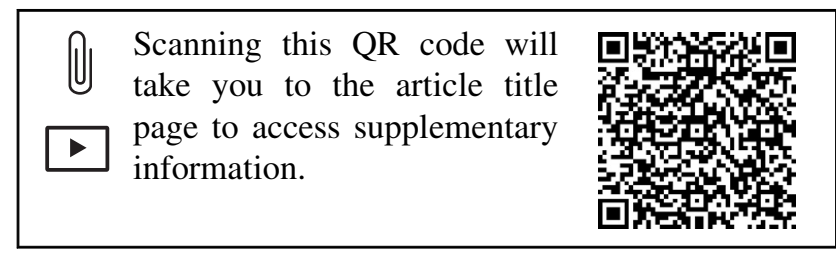




\section{Abbreviations and Acronyms \\ ATAAD $=$ acute Stanford type A aortic dissection \\ $\mathrm{CPB}=$ cardiopulmonary bypass \\ CTA = computed tomography angiography \\ FET $\quad=$ frozen elephant trunk \\ VIS = vasoactive-inotropic score}

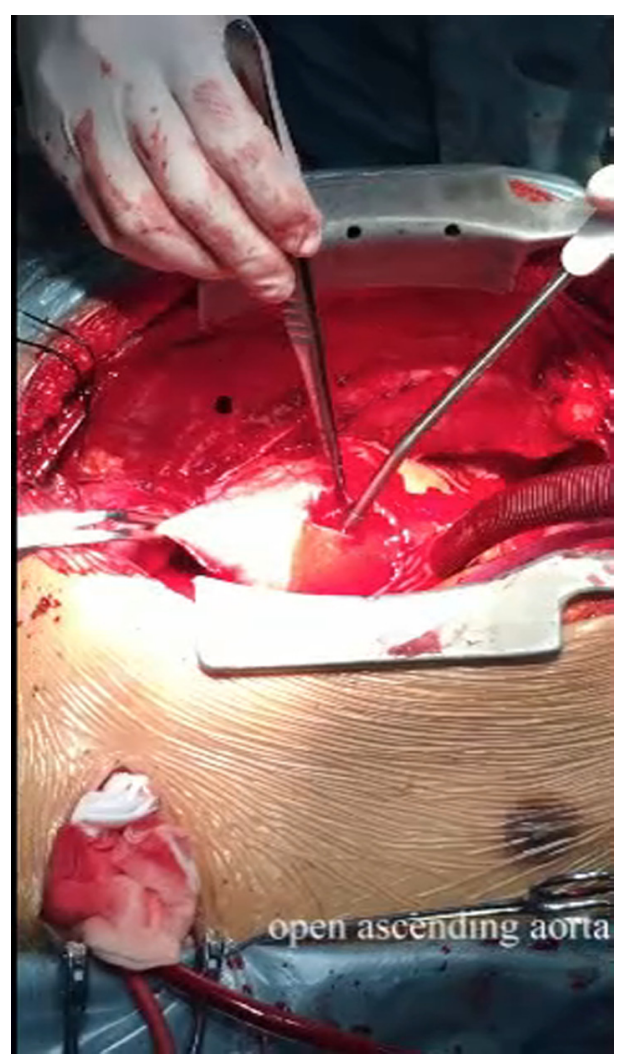

VIDEO 1. The surgical procedure of total arch replacement and frozen elephant trunk (FET). Video available at: https://www.jtcvs.org/article/ S0022-5223(18)32506-6/fulltext.

and after operation was measured through the radial and dorsalis pedis arterial line. A cerebrospinal fluid drainage catheter was inserted immediately after diagnosis of postoperative paraplegia in the cardiac intensive care unit.

\section{Data Collection and Analysis}

CTA was performed about 1 week after operation on all patients except those in critical status. Clinical data and perioperative CTA scans of patients were collected from the departmental database. The usage of these data for research was approved by the ethics committee of the Second Xiangya Hospital, Changsha, China. All procedures were performed in accordance with the ethical standards of the Institutional Research Committee and with the 1964 Helsinki Declaration and its later amendments or comparable ethical standards. Informed consent was waived by the committee because of the retrospective nature of the study. The use of these data for research has been approved by the ethics committee of the Second Xiangya Hospital, Changsha, China.

Hourly doses of all vasoactive agents were recorded after admission to the cardiac intensive care unit. Maximum vasoactive-inotropic score (VIS) was calculated in the first 24 hours using the following formula: VIS $=$ dopamine dose $(\mu \mathrm{g} / \mathrm{kg} / \mathrm{min})+$ dobutamine dose $(\mu \mathrm{g} / \mathrm{kg} /$ $\min )+10 \times$ milrinone dose $(\mu \mathrm{g} / \mathrm{kg} / \mathrm{min})+100 \times$ epinephrine dose $(\mu \mathrm{g} /$ $\mathrm{kg} / \mathrm{min})+100 \times$ norepinephrine dose $(\mu \mathrm{g} / \mathrm{kg} / \mathrm{min})+10,000 \times$ vasopressin dose (units $/ \mathrm{kg} / \mathrm{min}$ ). Upper-lower pressure gradients were calculated as the radial artery systolic pressure minus the dorsalis pedis artery systolic pressure.

On postoperative CTA scans, the slice with the narrowest true lumen was selected from the slices with complete thrombosis in the distal false lumen, and the areas of the true lumen and the descending aorta were 
TABLE 1. General characteristics of acute Stanford type A aortic dissection patients with or without postoperative paraplegia

\begin{tabular}{|c|c|c|c|}
\hline Variable & $\begin{array}{l}\text { Paraplegia group } \\
\quad(\mathbf{n}=\mathbf{5})\end{array}$ & $\begin{array}{l}\text { No paraplegia group } \\
\quad(\mathbf{n}=\mathbf{1 0 5})\end{array}$ & $P$ value \\
\hline \multicolumn{4}{|l|}{ Preoperative } \\
\hline Male, n (\%) & $5(100.0)$ & $81(77.1)$ & .513 \\
\hline Age, y & $47.6 \pm 7.1$ & $47.7 \pm 10.1$ & .988 \\
\hline Duration from symptoms to surgery, $\mathrm{h}$ & $43.0(39.5,86.5)$ & $54.0(37.5,82.5)$ & .780 \\
\hline Hypertension, $\mathrm{n}(\%)$ & $5(100.0)$ & $72(68.7)$ & .318 \\
\hline Diabetes, n $(\%)$ & $0(0.0)$ & $2(1.9)$ & .911 \\
\hline Marfan syndrome, n (\%) & $0(0.0)$ & $5(4.8)$ & .789 \\
\hline PND, n $(\%)$ & $1(20.0)$ & $5(4.8)$ & .249 \\
\hline Coronary heart disease, $\mathrm{n}(\%)$ & $0(0.0)$ & $4(3.8)$ & .828 \\
\hline Vascular surgery, n (\%) & $0(0.0)$ & $2(1.9)$ & .911 \\
\hline Cardiac valve surgery, $\mathrm{n}(\%)$ & $0(0.0)$ & $2(1.9)$ & .911 \\
\hline PCI surgery, $\mathrm{n}(\%)$ & $0(0.0)$ & $1(1.0)$ & .955 \\
\hline \multicolumn{4}{|l|}{ Operative } \\
\hline CPB time, $\min$ & $215.0(160.5,257.0)$ & $173.0(147.5,203.0)$ & .160 \\
\hline Aortic crossclamping time, $\min$ & $84.0(47.0,124.0)$ & $76.0(66.0,87.0)$ & .672 \\
\hline ACP time (lower body ischemic time), min & $17.0(16.5,20.5)$ & $17.0(15.0,19.0)$ & .518 \\
\hline Nasopharyngeal temperature, ${ }^{\circ} \mathrm{C}$ & $25.0(24.0,27.4)$ & $26.3(24.3,28.0)$ & .646 \\
\hline Rectal temperature, ${ }^{\circ} \mathrm{C}$ & $26.6(25.9,31.5)$ & $28.6(27.6,29.8)$ & .551 \\
\hline \multicolumn{4}{|l|}{ Postoperative } \\
\hline Postoperative minimum MAP $<70$ mm Hg, n (\%) & $1(20.0)$ & $2(1.9)$ & .131 \\
\hline Maximum first 24-hour VIS & $16(11,23)$ & $12(11,13)$ & .181 \\
\hline Upper-lower pressure gradient & $2.4 \pm 24.6$ & $-7.3 \pm 25.7$ & .451 \\
\hline \multicolumn{4}{|l|}{ Postoperative CTA scans* } \\
\hline False lumen thrombosis, $\mathrm{n}(\%)$ & $5(100.0)$ & $72(75.5)$ & .200 \\
\hline $\begin{array}{l}\text { Ratio of the area of the narrowest true lumen to } \\
\text { the area of the descending aorta }\end{array}$ & $0.09(0.07,0.17)$ & $0.31(0.18,0.50)$ & $.002 \dagger$ \\
\hline "Cutoff" phenomenon, n (\%) & $4(80.0)$ & $1(1.0)$ & $<.001 \dagger$ \\
\hline
\end{tabular}

Continuous variables are given as the mean \pm standard deviation or median (quartile; $\mathrm{Q}_{25}, \mathrm{Q}_{75}$ ); categorical variables are given as number of patients $(\%)$. Logistic regression analysis was used to identify the risk factors of paraplegia. $P N D$, Permanent neurologic deficit; $P C I$, percutaneous coronary intervention; $C P B$, cardiopulmonary bypass; $A C P$, antegrade cerebral perfusion; MAP, mean arterial pressure; VIS, vasoactive-inotropic score; CTA, computed tomography angiography. ${ }^{*}$ In the no paraplegia group, 9 patients did not undergo postoperative CTA. †ंSignificant association with $P<.05$.

measured by using the CAD2007 software (Autodesk Inc, San Rafael, Calif). The degree of compression of the true lumen was reflected by calculating the ratio of the area of the narrowest true lumen to the area of the descending aorta. The "cutoff" phenomenon was defined as the ratio $<0.1$ ( $90 \%$ occlusion), thrombus of the false lumen exceeding 2 -vertebra length, and the absence of contrast medium in the distal false lumen of the stented portion of the descending aorta.

For the patients with untreated intimal tears (presenting communication flow channels between the true and false lumens) beyond the distal end of the stent, we further counted the intimal tears and marked their locations by comparing pre- and postoperative CTA scans. We measured the distance from the distal end of the stent to the first untreated intimal tear and analyzed the relationship between the distance and the thrombus compression of the true lumen.

\section{Statistical Analyses}

Continuous variables are presented as the mean \pm standard deviation or median (quartile; $\mathrm{Q}_{25}, \mathrm{Q}_{75}$ ). Categorical variables are presented as frequency and percentage. The $\chi^{2}$ test was used. The risk factors of postoperative paraplegia were assessed using univariate logistical analysis. Data were analyzed using the SPSS 22.0 software (IBM Corp., Armonk, NY), and differences were considered significant at $P<.05$.

\section{RESULTS}

\section{Surgical and Postoperative Data}

Between December 2014 and September 2017, 110 patients with ATAAD, $86(78.2 \%)$ men and $24(21.8 \%)$ women with an average age of $48.0 \pm 10.0$ years (range, 26-69 years), underwent total arch replacement and FET.

All surgical procedures were completed successfully. The Bentall procedure $(\mathrm{n}=20,18.2 \%)$, Wheat procedure $(\mathrm{n}=4,3.6 \%)$, aortic valve commissuroplasty $(\mathrm{n}=25$, $22.7 \%)$, aortic Valsalva sinuplasty $(\mathrm{n}=27,24.5 \%)$, and coronary artery bypass grafting $(\mathrm{n}=5,4.5 \%)$ were performed when necessary. The 30-day mortality was $10.0 \%$ (11/110). The main postoperative complications were cardiac arrest $(\mathrm{n}=4,3.6 \%)$, permanent neurologic deficit $(\mathrm{n}=3,2.7 \%)$, renal failure $(\mathrm{n}=14,12.7 \%)$, and paraplegia $(\mathrm{n}=5,4.5 \%)$. For the 5 patients with paraplegia, 3 died in multiple organ dysfunction syndrome within 1 month after surgery, and 2 had their myodynamia reverted to grade 4 after spinal drainage and rehabilitation training. 

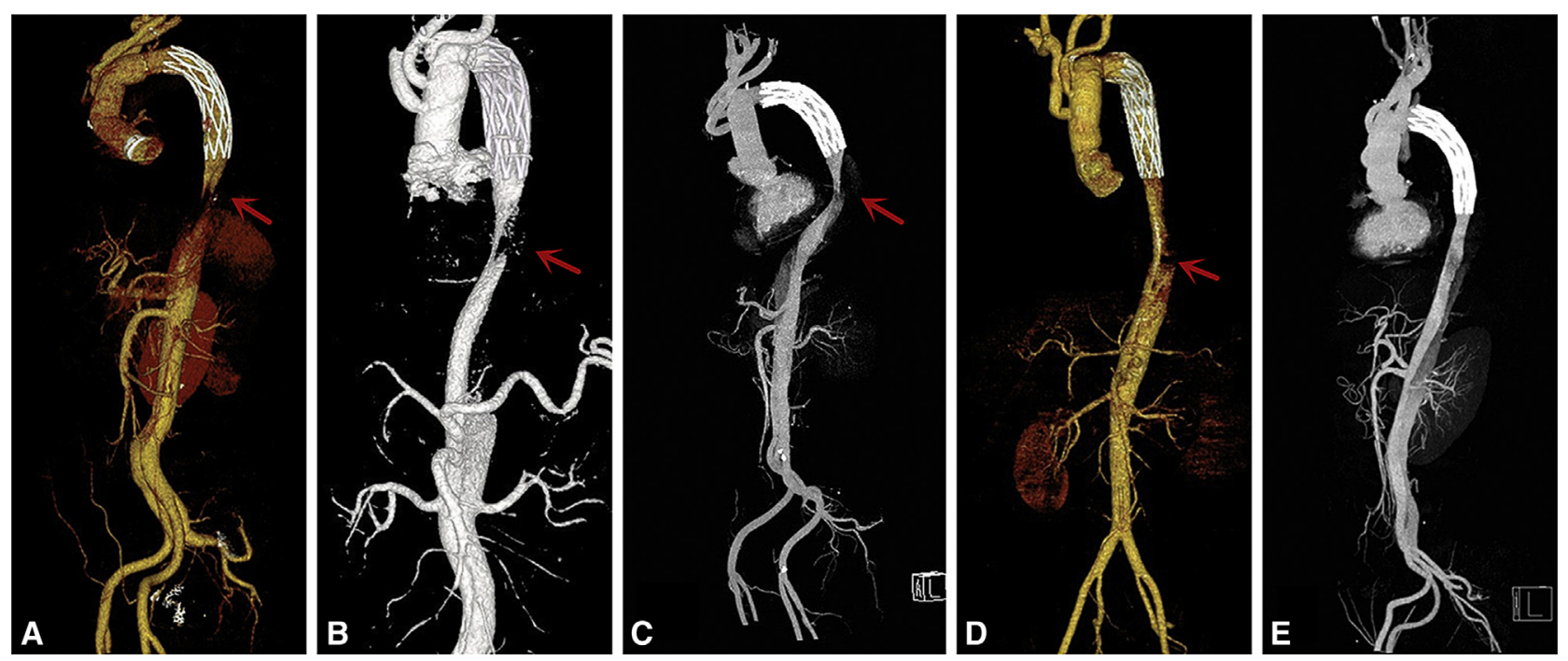

FIGURE 1. Postoperative CTA of the 5 patients with paraplegia. A-D, The compressed true lumens with a "cutoff" phenomenon (red arrows) were observed on postoperative CTA in 4 patients. E, No "cutoff" phenomenon was observed on postoperative CTA of the fifth patient with paraplegia.

\section{CTA Scans}

All 5 patients with paraplegia underwent early postoperative CTA to determine the cause of paraplegia. Among the 105 patients without paraplegia, 96 underwent postoperative CTA, and 9 (7 with early postoperative death, 1 with acute renal failure, and 1 with severe hypoxemia) did not. Among the 101 patients who underwent early postoperative CTA, $19(18.8 \%)$ had no distal tears (none had paraplegia), $70(69.3 \%)$ had untreated tears beyond the distal end of the stent ( 5 had paraplegia), and 12 could not be determined in terms of the existence of untreated distal tears because of the poor quality of preoperative CTA scans. CTA scans also showed that the distal end of the stent reached only to the vertebra $\mathrm{T} 7(\mathrm{n}=68,67.3 \%)$ or $\mathrm{T} 8(\mathrm{n}=33$, $32.7 \%$ ) level.

\section{Univariate Analysis of Postoperative Paraplegia}

Univariate analysis showed no associations between paraplegia and sex, age, duration from the occurrence of symptoms to surgery, medical history (hypertension, diabetes, Marfan syndrome, permanent neurologic deficit, coronary heart disease, vascular surgery, cardiac valve surgery and percutaneous coronary intervention surgery), CPB time, aortic crossclamping time, antegrade cerebral perfusion time (lower body ischemic time), temperature, postoperative hypotension, maximum first 24-hour VIS,

TABLE 2. Associations between potential risk factors and postoperative paraplegia

\begin{tabular}{|c|c|c|}
\hline Variable & OR $(95 \%$ CI $)$ & $P$ value \\
\hline \multicolumn{3}{|l|}{ Preoperative } \\
\hline Age, y & $0.88(0.36-2.13)$ & .775 \\
\hline PND, n $(\%)$ & $5.00(0.47-53.39)$ & .183 \\
\hline \multicolumn{3}{|l|}{ Operative } \\
\hline $\mathrm{CPB}$ time, $\min$ & $1.04(0.94-1.15)$ & .433 \\
\hline Aortic crossclamping time, min & $1.09(0.81-1.45)$ & .568 \\
\hline ACP time (lower body ischemic time), min & $1.01(0.86-1.18)$ & .923 \\
\hline Nasopharyngeal temperature, ${ }^{\circ} \mathrm{C}$ & $0.88(0.58-1.35)$ & .556 \\
\hline Rectal temperature, ${ }^{\circ} \mathrm{C}$ & $0.90(0.56-1.46)$ & .678 \\
\hline \multicolumn{3}{|l|}{ Postoperative } \\
\hline Postoperative minimum MAP $<70 \mathrm{~mm} \mathrm{Hg}, \mathrm{n}(\%)$ & $12.88(0.96-173.34)$ & .054 \\
\hline Maximum first-24-hour VIS & $1.11(0.96-1.27)$ & .156 \\
\hline \multicolumn{3}{|l|}{ Postoperative CTA scans* } \\
\hline Ratio of the area of the narrowest true lumen to the area of the descending aorta & & $<.001$ \\
\hline "Cutoff" phenomenon, n (\%) & & $<.001$ \\
\hline
\end{tabular}

$\overline{B o l d}$ type indicates significant association with $P<.05$. OR, Odds ratio; $C I$, confidence interval; $P N D$, permanent neurologic deficit; $C P B$, cardiopulmonary bypass; $A C P$, antegrade cerebral perfusion; $M A P$, mean arterial pressure; VIS, vasoactive-inotropic score; $C T A$, computed tomography angiography. *Reliable estimates of the odds ratios associated with these variables cannot be provided because of the small number of patients with paraplegia. 


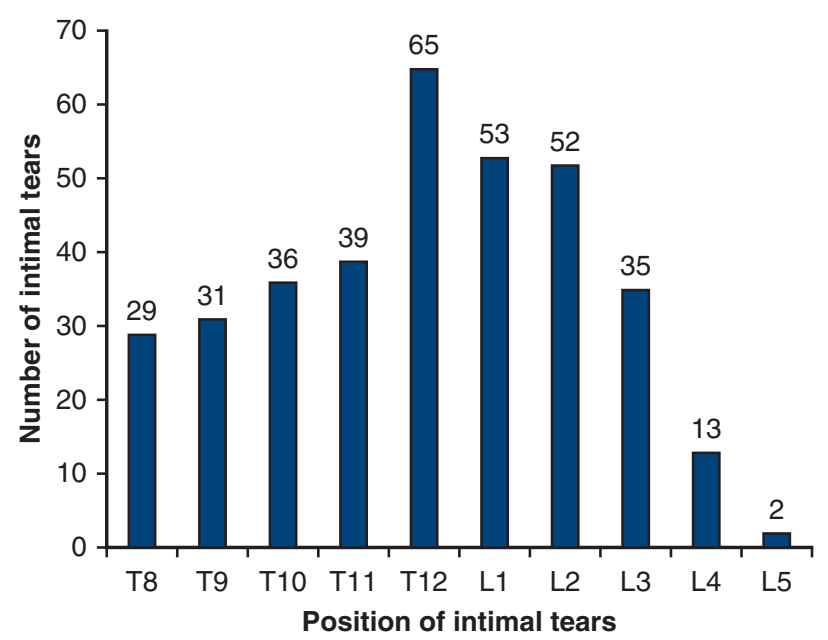

FIGURE 2. The distribution of untreated intimal tears beyond the distal end of the stent.

upper-lower pressure gradient, or false lumen thrombosis (Table 1). However, we found that 4 of the 5 patients with postoperative paraplegia had the following CTA features: severe compression of the true lumen and a "cutoff" phenomenon in the descending aorta caused by distal false lumen thrombosis (Figure 1). Univariate logistical analysis showed that postoperative paraplegia was associated with the ratio of the area of the narrowest true lumen to the area of the descending aorta and the "cutoff" phenomenon $(P<.05)$ (Table 2$)$.

\section{Distribution of Untreated Intimal Tears Beyond the Distal End of the Stent}

Of the 110 patients, $70(63.6 \%)$ had a total of 355 untreated tears beyond the distal end of the stent (Figure E1). Among the 355 tears, 209 (58.9\%) were located near the branches of celiac artery (the vertebra T11-L2 level), which were the predilection sites of intimal tears (Figure 2). All 70 patients had intimal tears at the vertebra T11-L2 level, and $60(85.7 \%)$ of them had at least 2 intimal tears (Figure E1).

\section{Associations Between the Distance From the Distal End of the Stent to the First Untreated Tear and the "Cutoff" Phenomenon and Paraplegia}

For the 70 with untreated intimal tears beyond the distal end of the stent, the distance from the distal end of the stent to the first untreated tear was $<30 \mathrm{~mm}$ in 35 patients, 30 to $60 \mathrm{~mm}$ in 15 patients, and $>60 \mathrm{~mm}$ in 20 patients. $\chi^{2}$ test showed that the patients with a distance $\geq 30 \mathrm{~mm}$ had a significantly greater rate of the "cutoff" phenomenon and paraplegia than those with a distance $<30 \mathrm{~mm}(P<.05)$ (Table 3). Further comparison showed that the occurrence rates of the "cutoff" phenomenon and paraplegia were greater in the $30 \mathrm{~mm}$ to $60 \mathrm{~mm}$ distance group than in the $>60$-mm distance group $(20.0 \%$ vs $10.0 \%, 26.6 \%$ vs $5.0 \%$, respectively), but there was no statistical significance. The detailed findings of the tears beyond the distal end of the stent in the 5 patients with paraplegia are shown in Figure 1 and Table E1.

\section{DISCUSSION}

Performing total arch replacement and FET to treat ATAAD involving the descending aorta is still under debate. Many surgeons are inclined to use only simple proximal repair, considering the high perioperative mortality and complication rates of extended arch repair. ${ }^{14} \mathrm{~A}$ metaanalysis showed that although conservative proximal repair decreased early postoperative mortality, the reoperation rate on the distal vessels significantly increased, and the longterm survival rate was not improved. ${ }^{15}$ Total arch replacement and FET could significantly improve distal vascular remodeling, decrease the reoperation rate, and create conditions for thoracoabdominal aorta replacement and thoracic endovascular aortic repair. ${ }^{9,16}$ Therefore, it was recommended by some surgeons. ${ }^{4,7}$ The 30 -day mortality in the present results was $10 \%$ and was acceptable as compared with the results of other studies. ${ }^{7,17-21}$ The outcome of surgery is associated with surgeons' experience. $^{1,16}$ With the experience increasing and surgical techniques being improved, the mortality is expected to decrease. ${ }^{9}$ Therefore, we recommended total

TABLE 3. Associations between the distance from the distal end of the stent to the first untreated intimal tear and false lumen thrombosis, "cutoff" phenomenon, and paraplegia

\begin{tabular}{|c|c|c|c|c|c|}
\hline Variable & \multicolumn{2}{|c|}{ Distance $<30 \mathrm{~mm}(\mathrm{n}=\mathbf{3 5})$} & \multicolumn{2}{|c|}{ Distance $\geq \mathbf{3 0} \mathrm{mm}(\mathrm{n}=\mathbf{3 5})$} & $P$ value \\
\hline False lumen thrombosis, n (\%) & \multicolumn{2}{|c|}{$30(85.7 \%)$} & \multicolumn{2}{|c|}{$33(94.3 \%)$} & .232 \\
\hline "Cutoff" phenomenon, n (\%) & \multicolumn{2}{|c|}{$0(0.0 \%)$} & \multicolumn{2}{|c|}{$5(14.3 \%)$} & $.027^{*}$ \\
\hline Paraplegia, n (\%) & \multicolumn{2}{|c|}{$0(0.0 \%)$} & \multicolumn{2}{|c|}{$5(14.3 \%)$} & $.027 *$ \\
\hline Variable & Distance $<30 \mathrm{~mm}(\mathrm{n}=35)$ & Distan & $(n=15)$ & Distance $>60$ & \\
\hline False lumen thrombosis, $\mathrm{n}(\%)$ & $30(85.7 \%)$ & & & $18(90$ & .999 \\
\hline "Cutoff" phenomenon, n (\%) & $0(0.0 \%)$ & & & $2(10$ & $.021 *$ \\
\hline Paraplegia, n (\%) & $0(0.0 \%)$ & & & $1(5$. & $.004 *$ \\
\hline
\end{tabular}

Fisher exact test for comparing the outcomes in 3 different groups. All data presented as number of patients (\%). *Significant association with $P<.05$. 

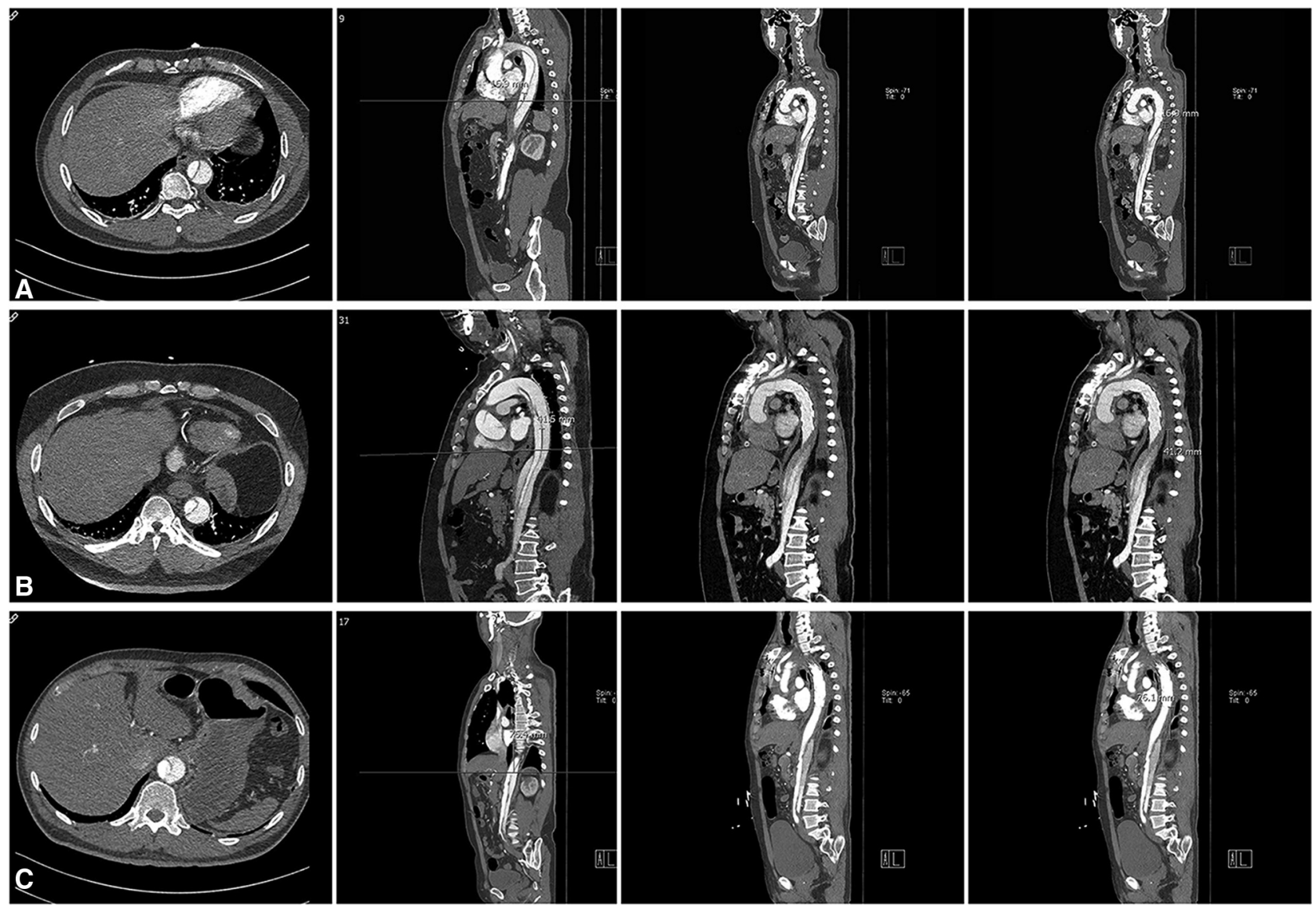

FIGURE 3. The existence and position of the first untreated tear beyond the distal end of the stent was determined by comparing pre- and postoperative CTA. The distance from the distal end of the stent to the first untreated tear was measured. Thrombosis is observed at the tear location. (A: a patient with a distance of $<30 \mathrm{~mm}$; B: a patient with a distance of $30-60 \mathrm{~mm}$; C: a patient with a distance of $>60 \mathrm{~mm}$ ).

arch replacement and FET for ATAAD involving the arch and descending aorta. How to improve the surgical techniques and to decrease postoperative complications remains as a major concern of this surgery.

It cannot be ignored that total arch replacement and FET has a greater rate of postoperative paraplegia than simple proximal repair alone. ${ }^{9}$ Postoperative paraplegia, in turn, will significantly increase mortality and disability rates. In the present study, the rate of postoperative paraplegia was $4.5 \%(5 / 110)$. Three of the 5 patients with paraplegia died within 1 month after surgery. Previous studies have shown that ischemic injury to the spinal cord that induced paraplegia was closely related to lower body ischemic time and temperature during the selective cerebral perfusion, segmental artery obstruction by the stent, and postoperative hypotension. ${ }^{11}$ Surgeons from Johann Wolfgang Goethe University thought that $32^{\circ} \mathrm{C}$ to $34^{\circ} \mathrm{C}$ for 15 minutes, $30^{\circ} \mathrm{C}$ to $32^{\circ} \mathrm{C}$ for 30 minutes, and $28^{\circ} \mathrm{C}$ for $\geq 45$ minutes were safe for the spinal cord. ${ }^{22}$ In the present study, the average rectal temperature was $27.2^{\circ} \mathrm{C}\left(24.4^{\circ} \mathrm{C}, 32.0^{\circ} \mathrm{C}\right)$, and the average lower body ischemic time was 17.0 minutes
(14.0, 30.0 minutes); all temperatures and duration were in safe ranges. The elephant trunk stents were short $(12.0 \mathrm{~cm})$, and none of them extended beyond the vertebra T8 level. Only 1 paraplegia patient had postoperative hypotension. Notably, this patient's postoperative CTA scans did not show a "cutoff" phenomenon, but the false lumen thrombosis (Figure 1, E).

We analyzed the early postoperative CTA scans of the 5 patients with paraplegia and found a characteristic "cutoff" phenomenon at the distal end of the stent in 4 patients (Figure 1). Postoperative paraplegia was associated with the "cutoff" phenomenon $(P<.05)$. Paraplegia did not occur in 19 patients who had no distal tears. Some researchers found that the false lumen was rich of thrombosis in patients with paraplegia. ${ }^{11,18}$ We further found that the distance from the distal end of the stent to the first untreated tear was closely related to the "cutoff" phenomenon and paraplegia $(P<.05$, Table 3$)$. The blind end of the false lumen between the distal end of the stent and the first untreated tear would be prone to thrombosis. Meanwhile, the high adaptability of the intima in acute 

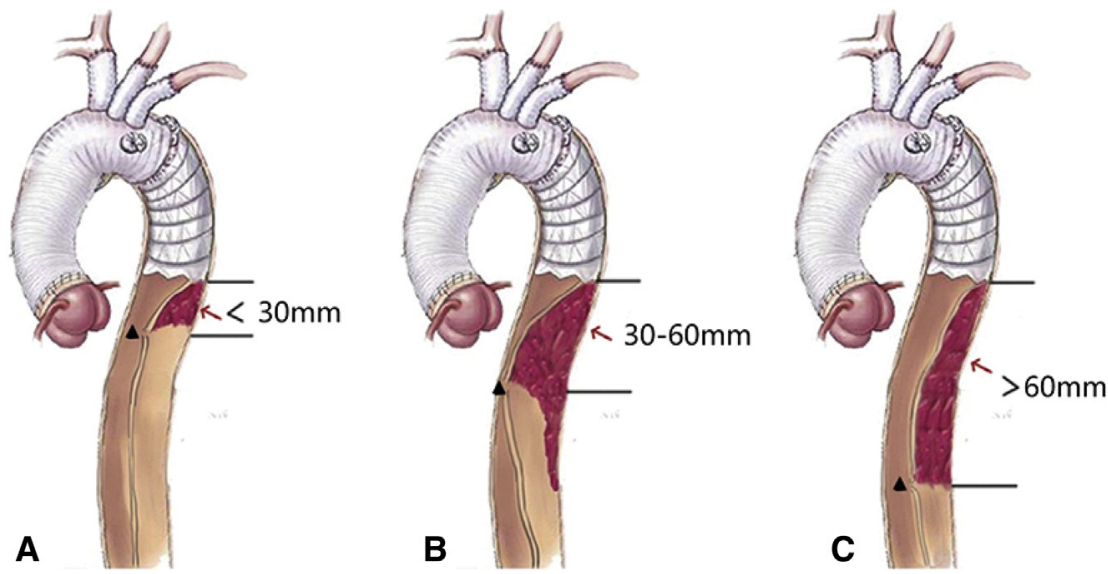

FIGURE 4. Different distances from the distal end of the stent to the first untreated tear result in different thrombosis models (black triangles indicate the location of the first untreated tear). A, When the distance is short $(<30 \mathrm{~mm})$, the thrombosis is immature or has difficulty forming in the blind end of the false lumen between the distal end of the stent and the first untreated tear. B-C, When the distance is long ( $>30 \mathrm{~mm})$, a long blind end is prone to thrombosis, and the intimal flap is pushed to the true lumen. B, When the distance is $30-60 \mathrm{~mm}$, the intimal flap being pushed to the true lumen would be long enough to squeeze the true lumen. C, When the distance is $>60 \mathrm{~mm}$, the pressure of the false lumen may be insufficient to push the intimal flap to squeeze the true lumen.

aortic dissection facilitates the compression by the pressure of the false lumen. If the distance from the distal end of the stent to the first untreated tear is adequately short $(<30 \mathrm{~mm})$, the blind end is short, and the blood flow in the true and false lumens can communicate with each other. Therefore, thrombosis is immature or has difficulty forming in the blind end (Figure 3, A, and Figure 4, A). Although the intimal flap will be pushed to the true lumen, it is too short to occlude the true lumen and completely cut off the distal blood flow. Therefore, the distal end of the intimal tear presents a double-lumen blood supply and may not cause ischemic injury to the distal organs and the spinal cord.

As shown in Table 3, no "cutoff" phenomenon and paraplegia were reported in the patients with the distance $<30 \mathrm{~mm}$. If the distance is $\geq 30 \mathrm{~mm}$, a long blind end would be prone to thrombosis in the false lumen, and the intimal flap being pushed to the true lumen would be long enough to squeeze the true lumen. If the segmental artery originates from the false lumen, it may be occluded by the thrombus. If the segmental artery originates from the true lumen, the blood flow may be decreased significantly by compression of the intimal flap. The aforementioned 2 factors may result in ischemic injury to the spinal cord and paraplegia (Figures 1, $A-D, 3, B$ and $C$, and $4, B$ and $C$ ). We further found that the occurrence rates of the "cutoff" phenomenon and paraplegia was greater in the $30 \mathrm{~mm}$ to $60 \mathrm{~mm}$ distance group than in the $>60 \mathrm{~mm}$ distance group. However, there was no statistical significance, which may be explained by the small sample size in the present study. Presumably, if the distance is adequately long (eg, >60 mm), the long blind end may develop thrombus easily. However, the pressure of the false lumen is insufficient to push the intimal flap to squeeze the true lumen, reducing the "cutoff" of distal blood flow and causing spinal cord ischemic injury (Figure 3, $C$, and $4, C$ ). In contrast, the importance of the lower thoracic segmental artery for blood supply to the spinal cord is increasingly recognized. ${ }^{23,24}$ The "cutoff" phenomenon occurred in the $30 \mathrm{~mm}$ to $60 \mathrm{~mm}$ distance group is located only in the lower thoracic aorta. In theory, the rate of paraplegia in this group should be greater than that in the $>60 \mathrm{~mm}$ distance group. Certainly, this corollary needs to be further confirmed.

The "cutoff" phenomenon of the descending aorta or paraplegia did not occur in the $>30 \mathrm{~mm}$ distance group, suggesting the existence of other factors that influence the formation of thrombus in the distal false lumen and severe compression of the true lumen, such as elasticity of the descending aorta, coagulation differences, and the existence of multiple untreated intimal tears beyond the distal end of the stent. The full communication between the true and false lumens decreases the development of extensive thrombosis in the false lumen (Figure E2). ${ }^{25}$

The length of the elephant trunk stent in extended arch repair is another concern. ${ }^{4}$ Many surgeons recommend using a short FET stent to decrease the direct coverage to the segmental arteries and ensure the blood supply to the spinal cord. ${ }^{26}$ According to our experience, we speculate that using a short stent alone is insufficient to avoid postoperative paraplegia. On the basis of our presumption of the "cutoff" phenomenon mentioned previously and the results from another study, ${ }^{10}$ we suggest that the length of the elephant trunk stent should be extended to the vertebra T9 level to make the distance from the distal end of the stent to the first untreated tear in the safe range $(<30 \mathrm{~mm})$. Although this improvement may shorten the distance 
from $>60 \mathrm{~mm}$ to 30 to $60 \mathrm{~mm}$, thrombosis-related "cutoff" phenomenon may be avoided due to the existence of multiple intimal tears at the vertebra T11-L2 level in most patients (Figure 2 and Figure E1) and full communication between the true and false lumens. Implanting a bare metal stent at the distal end of the trunk to solve the "cutoff" phenomenon is an alternative strategy, but the timing and indications of using a bare stent is still unknown and needs to be explored further. In addition, improving surgical techniques, reducing the use of hemostatic drugs, or performing adequate anticoagulation procedures might contribute to reducing early thrombosis of the false lumen and decreasing the risk of ischemic injury to the spinal cord.

The present study focused on patients with ATAAD who were treated using the FET. This procedure may not be suitable for chronic Stanford type A aortic dissection or aneurysm. This is a retrospective study performed by a single operation group, the sample size is relatively small, and the findings need to be further validated.

\section{CONCLUSIONS}

In general, total arch replacement and FET is safe and feasible for ATAAD involving the descending aorta. Early postoperative paraplegia is associated with the "cutoff" phenomenon in the lower descending aorta. The position of the first untreated intimal tear may be related with the "cutoff" phenomenon and paraplegia. We believe that using a short stent alone is insufficient to avoid postoperative paraplegia. Surgeons should pay more attention to the first untreated intimal tear beyond the distal end of the stent, which may be a risk factor of postoperative paraplegia.

\section{Conflict of Interest Statement}

Authors have nothing to disclose with regard to commercial support.

\section{References}

1. Erbel R, Aboyans V, Boileau C, Bossone E, Bartolomeo RD, Eggebrecht H, et al. 2014 ESC Guidelines on the diagnosis and treatment of aortic diseases: Document covering acute and chronic aortic diseases of the thoracic and abdominal aorta of the adult. The Task Force for the Diagnosis and Treatment of Aortic Diseases of the European Society of Cardiology (ESC). Eur Heart J. 2014;35:2873-926.

2. Karck M, Chavan A, Hagl C, Friedrich H, Galanski M, Haverich A. The frozen elephant trunk technique: a new treatment for thoracic aortic aneurysms. $J$ Thorac Cardiovasc Surg. 2003;125:1550-3.

3. Ma WG, Zheng J, Dong SB, Lu W, Sun K, Qi RD, et al. Sun's procedure of total arch replacement using a tetrafurcated graft with stented elephant trunk implantation: analysis of early outcome in 398 patients with acute type A aortic dissection. Ann Cardiothorac Surg. 2013;2:621-8.

4. Tian DH, Wan B, Di Eusanio M, Black D, Yan TD. A systematic review and meta-analysis on the safety and efficacy of the frozen elephant trunk technique in aortic arch surgery. Ann Cardiothorac Surg. 2013;2:581-91.

5. Hoffman A, Damberg AL, Schalte G, Mahnken AH, Raweh A, Autschbach R. Thoracic stent graft sizing for frozen elephant trunk repair in acute type A dissection. J Thorac Cardiovasc Surg. 2013;145:964-9.

6. Haverich A. Aortic arch replacement with frozen elephant trunk-when not to use it. Ann Cardiothorac Surg. 2013;2:592-6.
7. Leontyev S, Misfeld M, Daviewala P, Borger MA, Etz CD, Belaev S, et al. Earlyand medium-term results after aortic arch replacement with frozen elephant trunk techniques-a single center study. Ann Cardiothorac Surg. 2013;2:606-11.

8. Uchida N, Katayama A, Tamura K, Sutoh M, Kuraoka M, Murao N, et al. Longterm results of the frozen elephant trunk technique for extended aortic arch disease. Eur J Cardiothorac Surg. 2010;37:1338-45.

9. Di Bartolomeo R, Pantaleo A, Berretta P, Murana G, Castrovinci S, Cefarelli M, et al. Frozen elephant trunk surgery in acute aortic dissection. J Thorac Cardiovasc Surg. 2015;149:S105-9.

10. Katayama K, Uchida N, Katayama A, Takahashi S, Takasaki T, Kurosaki T, et al. Multiple factors predict the risk of spinal cord injury after the frozen elephant trunk technique for extended thoracic aortic disease. Eur J Cardiothorac Surg. 2015;47:616-20.

11. Sun LZ, Qi RD, Chang Q, Zhu JM, Liu YM, Yu CT, et al. Surgery for acute type A dissection using total arch replacement combined with stented elephant trunk implantation: experience with 107 patients. J Thorac Cardiovasc Surg. 2009;138: 1358-62.

12. Sun L, Qi R, Zhu J, Liu Y, Chang Q, Zheng J. Repair of acute type A dissection: our experiences and results. Ann Thorac Surg. 2011;91:1147-52.

13. Ma WG, Zhu JM, Zheng J, Liu YM, Ziganshin BA, Elefteriades JA, et al. Sun's procedure for complex aortic arch repair: total arch replacement using a tetrafurcate graft with stented elephant trunk implantation. Ann Cardiothorac Surg. 2013;2:642-8

14. Hata M, Orime Y, Wakui S, Nakamura T, Hinoura R, Akiyama K. Efficacy of limited proximal arch replacement for type A acute aortic dissection with critical complications. Gen Thorac Cardiovasc Surg. 2016;64:651-6.

15. Yan Y, Xu L, Zhang H, Xu ZY, Ding XY, Wang SW, et al. Proximal aortic repair versus extensive aortic repair in the treatment of acute type A aortic dissection: a meta-analysis. Eur J Cardiothorac Surg. 2016;49:1392-401.

16. Roselli EE, Tong MZ, Bakaeen FG. Frozen elephant trunk for DeBakey type 1 dissection: the Cleveland Clinic technique. Ann Cardiothorac Surg. 2016;5: $251-5$.

17. Hirnle T, Stankiewicz A, Matlak K, Frank M, Trzcinski R, Lejko A, et al. Singlecentre experience in surgery of acute aortic type A dissection and true aortic arch aneurysm. Kardiol Pol. 2016;74:994-1001.

18. Martens A, Beckmann E, Kaufeld T, Umminger J, Fleissner F, Koigeldiyev N, et al. Total aortic arch repair: risk factor analysis and follow-up in 199 patients. Eur J Cardiothorac Surg. 2016;50:940-8.

19. Chen X, Huang F, Xu M, Wang L, Jiang Y, Xiao L, et al. The stented elephant trunk procedure combined total arch replacement for Debakey I aortic dissection: operative result and follow-up. Interact Cardiovasc Thorac Surg. 2010;11: 594-8.

20. Lin HH, Liao SF, Wu CF, Li PC, Li ML. Outcome of frozen elephant trunk technique for acute type A aortic dissection: as systematic review and meta-analysis. Medicine (Baltimore). 2015;94:e694.

21. Easo J, Weigang E, Holzl PP, Horst M, Hoffmann I, Blettner M, et al. Influence of operative strategy for the aortic arch in DeBakey type I aortic dissection: analysis of the German Registry for Acute Aortic Dissection Type A. J Thorac Cardiovasc Surg. 2012;144:617-23.

22. Zierer A, El-Sayed Ahmad A, Papadopoulos N, Moritz A, Diegeler A, Urbanski PP. Selective antegrade cerebral perfusion and mild $\left(28^{\circ} \mathrm{C}-30^{\circ} \mathrm{C}\right)$ systemic hypothermic circulatory arrest for aortic arch replacement: results from 1002 patients. J Thorac Cardiovasc Surg. 2012;144:1042-50.

23. Kamada T, Yoshioka K, Tanaka R, Makita S, Abiko A, Mukaida M, et al. Strategy for thoracic endovascular aortic repair based on collateral circulation to the artery of Adamkiewicz. Surg Today. 2016;46:1024-30.

24. Zoli S, Roder F, Etz CD, Brenner RM, Bodian CA, Lin HM, et al. Predicting the risk of paraplegia after thoracic and thoracoabdominal aneurysm repair. Ann Thorac Surg. 2010;90:1237-44; discussion 45.

25. Di Eusanio M, Pantaleo A, Murana G, Pellicciari G, Castrovinci S, Berretta P, et al. Frozen elephant trunk surgery-the Bologna's experience. Ann Cardiothorac Surg. 2013;2:597-605.

26. Nishi H, Mitsuno M, Tanaka H, Ryomoto M, Fukui S, Miyamoto Y. Spinal cord injury in patients undergoing total arch replacement: a cautionary note for use of the long elephant technique. J Thorac Cardiovasc Surg. 2011;142:1084-9.

Key Words: acute Stanford type A aortic dissection, total arch replacement, frozen elephant trunk, intimal tear, paraplegia 


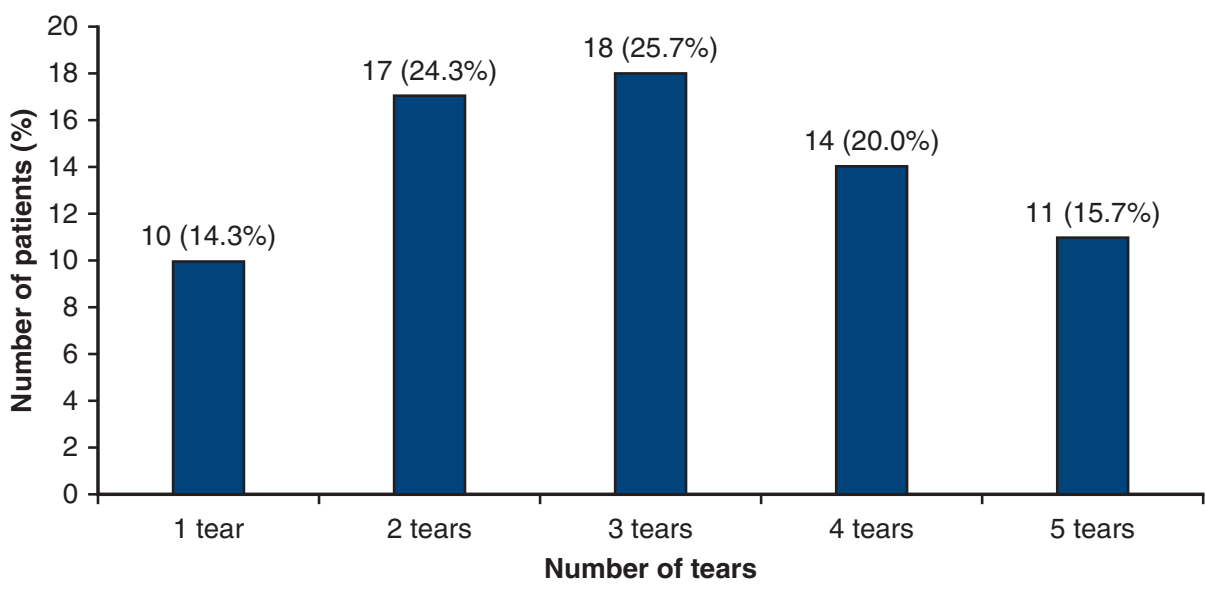

FIGURE E1. The distribution of untreated intimal tears in the 70 patients.
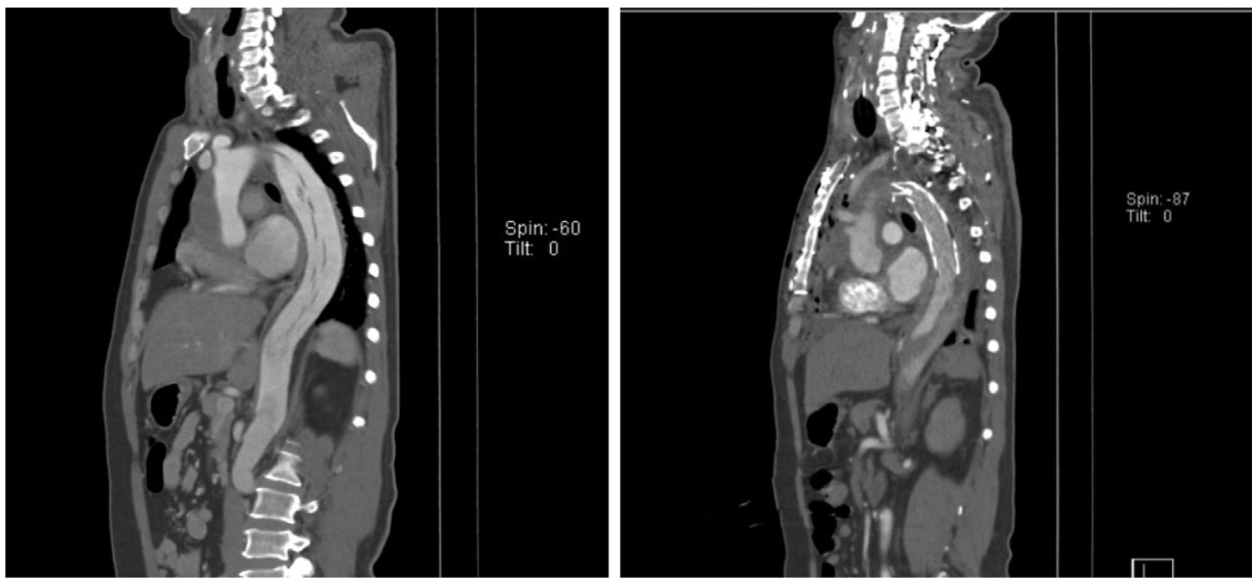

FIGURE E2. With continuous multiple tears, it is difficult for a thrombus to form because of the blood flow communication between the true and false lumens.

TABLE E1. The detailed findings of the 5 patients with paraplegia

\begin{tabular}{|c|c|c|c|c|c|c|}
\hline \multirow[b]{2}{*}{ Patient } & \multirow[b]{2}{*}{$\begin{array}{c}\text { Postoperative } \\
\text { minimum MAP } \\
<70 \text { mm Hg, } \\
\text { yes } / \text { no } \\
\end{array}$} & \multirow[b]{2}{*}{$\begin{array}{c}\text { False lumen } \\
\text { thrombosis, } \\
\text { yes/no }\end{array}$} & \multicolumn{4}{|c|}{ Postoperative CTA scans } \\
\hline & & & $\begin{array}{c}\text { “Cutoff” } \\
\text { phenomenon, } \\
\text { yes/no }\end{array}$ & $\begin{array}{c}\text { Number of } \\
\text { tears beyond } \\
\text { the stent }\end{array}$ & $\begin{array}{c}\text { The position } \\
\text { of the first } \\
\text { untreated tear }\end{array}$ & $\begin{array}{l}\text { The distance from } \\
\text { the distal end of the } \\
\text { stent to the first } \\
\text { untreated tear, mm }\end{array}$ \\
\hline A & No & Yes & Yes & 9 & T9 & 41.1 \\
\hline B & No & Yes & Yes & 4 & $\mathrm{~T} 8$ & 35.6 \\
\hline $\mathrm{C}$ & No & Yes & Yes & 7 & $\mathrm{~T} 9$ & 52.0 \\
\hline $\mathrm{D}$ & No & Yes & Yes & 4 & $\mathrm{~T} 10$ & 65.6 \\
\hline $\mathrm{E}$ & Yes & Yes & No & 5 & $\mathrm{~T} 8$ & 56.2 \\
\hline
\end{tabular}

MAP, Mean arterial pressure; CTA, computed tomography angiography. 